\title{
Managing Welfare and Antimicrobial-Resistance Issues in Treating Foot-and-Mouth Disease Lesions: A New Therapeutic Approach
}

This article was published in the following Dove Press journal: Veterinary Medicine: Research and Reports

\author{
Peter Windsor (1D' \\ Syseng Khounsy ${ }^{2}$ \\ Francesca Earp (1D) \\ Isabel MacPhillamy' \\ James Young' \\ Russell Bush' \\ 'The University of Sydney, Sydney School \\ of Veterinary Science, Camden, NSW, \\ 2570, Australia; ${ }^{2}$ Department of \\ Livestock and Fisheries, Ministry of \\ Livestock and Fisheries, Vientiane, Lao \\ People's Democratic Republic
}

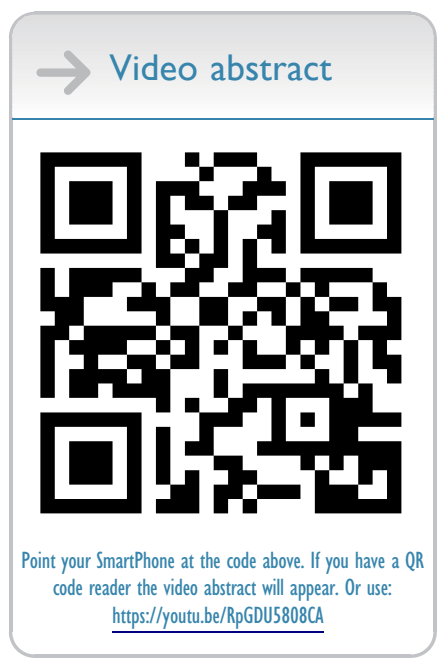

Correspondence: Peter Windsor

The University of Sydney, Sydney School

of Veterinary Science, Camden, NSW

2570, Australia

Tel +6I 204-3898-3367

Email peter.windsor@sydney.edu.au
Introduction: Foot-and-mouth disease (FMD) causes negative impacts on global food security, the livestock trade, national economies, and farming-family livelihoods, particularly in resourcepoor developing countries with inadequate biosecurity and low levels of vaccination from inadequate veterinary services. As smallholder farmers have limited understanding of diseaserisk management, their focus in FMD outbreaks is on accessing clinically effective therapies. However, most are provided inappropriate traditional treatments and/or topical or parenteral antibiotics, often delivered by paraveterinarians inadequately trained in antimicrobial custodianship. This results in negative financial impacts on livelihoods plus risks of food safety and development of antimicrobial resistance. We report the use of a novel pain-relief therapy for FMD.

Methods: Clinical examinations in an outbreak of suspected FMD in April 2019 in Muang Khay village in Luang Prabang province, Laos confirmed signs and lesions of severe, subacute, ulcerative glossitis and interdigital dermatitis, typical of FMD. All affected buffalo $(n=99)$ and cattle $(n=37)$ presented for treatment in a population of 238 large ruminants, from 15 of 136 households, were administered a topical anesthetic pain-relief product (PRP) wound gel by spray-on (10-30 mL per animal) formulation developed for aversive husbandry procedures (Tri-Solfen, Animal Ethics, Australia).

Results: Treatment with PRP resulted in immediate improvement in demeanor and locomotion, and no adverse events were observed. On follow-up interview, all owners confirmed that their animals were eating within 2 days and lesions had healed within 5 days. Having experienced the positive clinical impacts of PRP on affected animals, these and surrounding farmers were keen to purchase the PRP for future use. The veterinary authorities rapidly registered the PRP for FMD therapy in Laos due to the observed efficacy.

Discussion: These findings suggest a potential paradigm shift from treating FMD with expensive antimicrobials, which risks antimicrobial resistance, to a new, less expensive therapeutic approach that reduces animal suffering and may motivate farmers to report disease to access treatment. Use of the PRP is suggested as an innovation that may improve future FMD management, particularly in developing countries.

Keywords: Laos, cattle, buffalo, therapy, topical anesthesia, antisepsis

\section{Introduction}

Foot-and-mouth disease (FMD) is an infectious viral disease affecting farmed artiodactyls and wildlife, particularly cattle, buffalo, pigs, and small ruminants, with signs characterized by fever, salivation, and vesicles in the mouth, muzzle, dental pad, tongue, teats, and feet. Rupture of the vesicles causes painful swelling 
and ulcerations of the oral and coronary band lesions, with depression, inappetence, lameness, recumbency, loss of body condition, and occasionally, mastitis and abortion. FMD is considered the most important of animal diseases, as globally there are huge numbers of animals affected. Increasingly, the socioeconomic effects of the disease and importance of control are being recognized. ${ }^{1-3}$ Direct losses are from reduced production and changes in herd structure, with indirect losses from the significant costs of FMD control and management, including treatment, reduced access to markets, and limited use of improved production technologies. The annual impact of FMD from production losses and vaccination alone has been estimated at approximately US $\$ 5$ billion. ${ }^{4}$ As the majority of the global burden of FMD falls on the world's poorest communities, particularly those most dependent on livestock in developing countries, this lost productivity contributes to greenhouse-gas concerns from large ruminantproduction inefficiencies, but most importantly, creates food insecurity and contributes to human malnutrition. 5,6

In Laos (Lao People's Democratic Republic), FMD has been shown to perpetuate the cycle of smallholder poverty through reduced large-ruminant production, interference with market access for the trading of livestock and their products, and importantly, imposing farming-household financial losses from the costs of treatment. ${ }^{7}$ Despite significant national and multilateral efforts to control FMD over the past two decades, including active participation in the Office International des Epizooties (OIE [World Organisation for Animal Health])-led South East Asia China Foot-and-Mouth Disease (SEACFMD) campaign and successful delivery of a large-scale vaccination program in northern Laos that effectively suppressed recognition of FMD outbreaks, ${ }^{8}$ endemic FMD viruses (FMDVs) have continued to circulate in Laos. Threats of current and emerging FMDVs have increased as transboundary animal movements in the region have intensified from increasing regional demand for meat. ${ }^{6,9}$ In Laos, smallholders produce $>94 \%$ of all livestock products, ${ }^{10}$ yet FMD presents a significant barrier to efficient livestock production, with losses from FMD in 2011 estimated at almost 12\% of the predicted farm-gate value of the national large-ruminant herd. ${ }^{11}$ At the smallholder level, direct and indirect losses may amount to as much as $60 \%$ of the annual household income, particularly where parenteral antibiotics are administered, causing adverse financial impacts on households from treatment for FMD.${ }^{11}$ However, as underreporting of outbreaks in Laos and other Greater Mekong-subregion countries occurs commonly, the incidence and impact of FMD on smallholder farmers has generally been underestimated. ${ }^{3,6,7}$

FMD lesions are extremely painful for affected animals, causing lameness, inappetence, and dysphagia from pain on eating and drinking, leading to rapid loss of condition, with ulcers often taking weeks to heal. There is no specific curative treatment for FMD. However, during FMD outbreaks, the priority of farmers is to gain access to therapies that may reduce morbidity, assist their animals to recovery, and prevent mortalities. Unfortunately, most affected animals are provided inappropriate and inefficacious therapies, including a range of mostly astringent traditional therapies or topical and/or parenteral antibiotics, often delivered by paraveterinarians inadequately trained in therapeutics and antimicrobial custodianship. $^{7,11}$ This results in negative financial impacts on livelihoods plus risks of food safety and development of antimicrobial resistance (AMR). In a recent report from neighboring Cambodia, almost $90 \%$ of surveyed village animal health workers from two provinces admitted that they used antibiotics to treat FMD-affected animals. ${ }^{12}$ In addition to antibiotics, affected animals may be treated with mild disinfectants, occasionally anti-inflammatory drugs, and in many rural communities in Laos, lesions may be treated with traditional therapies, including application of lemon juice or the scraping of lesions with the bark of trees. ${ }^{3,7}$ In other countries, anecdotal reports include the use of soda-ash solution for washing the lesions and application of honey and various astringent substances (PW, personal observations). Many of these therapies are very likely to induce pain and increase animal suffering during FMD outbreaks.

In recent years, a proprietary topical anesthetic and antiseptic wound-care product that is applied directly to wounds in animals to mitigate pain, bleeding, and infection (Tri-Solfen; Animal Ethics, Australia) has become available for improved animal welfare. ${ }^{13-15}$ This woundformulation pain-relief product (PRP) contains two local anesthetics - lidocaine for rapid onset and bupivacaine for prolonged duration of anesthetic effect - adrenalin to delay systemic absorption of local anesthetic actives, and cetrimide for antiseptic activity, all within a gel matrix that provides wound coverage. The PRP is registered and has been widely and frequently used in various livestock species, particularly sheep and cattle in Australia and more recently New Zealand, to mitigate pain due to wounds from surgical husbandry procedures, including castration, tail 
docking, dehorning, and mulesing. ${ }^{14,15}$ It is applied directly to wounds using a "no-touch" technique as a metered-dose "spray-and-stay" formulation that adheres to the wound, providing a long-lasting coating over lesions that enables prolonged delivery of the actives and encourages healing. ${ }^{13}$ Numerous studies have reported significant reductions in pain associated with PRP therapy of wounds in sheep, cattle, and pigs, and it has also proven effective to mitigate pain associated with bovine hoof lesions, resulting in improved management of lameness. ${ }^{13,16}$

Following extensive research conducted on pain management for improved welfare for animals during husbandry procedures, ${ }^{13}$ it was hypothesized that the use of this PRP may similarly mitigate pain of FMD lesions and assist recovery. We sought to establish if the potential for a PRP to improve the demeanor, feeding, locomotion, and lesion recovery of FMD-affected animals during disease outbreaks would be of interest to smallholder farmers in Laos and beyond. Therefore, an observational clinical field trial was conducted during an outbreak of FMD in Laos in April 2019, to examine use of the PRP potentially to mitigate suffering and distress and improve recovery in FMD-affected large ruminants. This paper provides a case report documenting qualitative observations from this firstevent investigation of a new approach to therapy for FMD.

\section{Methods}

The methodologies used in this case study complied with the National Health and Medical Research Council's National Statement on Ethical Conduct in Human Research (2007) and the Universities Australia Australian Code for the Responsible Conduct of Research. The study was conducted in association with projects approved by the animal and human ethics approval process of the University of Sydney Ethics Committee (projects 2015/ 765 and 2014/783, respectively), and all participants provided verbal informed consent. The committee approved verbal informed consent for collection of animal blood samples, tissue, farmer interviews, and participation in videos and images, as written consent was unavailable due to farmer illiteracy.

Following a verbal report received by the authors and shared with the veterinary authorities (Department of Livestock and Fisheries [DLF]) of Laos on April 11, 2019 of an outbreak of FMD that had just commenced in large ruminants in Muang Khay village, $23 \mathrm{~km}$ from Luang Prabang city in Luang Prabang province, northern Laos, an observational trial of the PRP for FMD was proposed. As this village provides rental buffalo to the local buffalo dairy to produce the unique buffalo dairy products that have recently become available in Laos, the villagers were highly motivated to have their animals treated with "something new that may help them recover quickly". The DLF field staff verified the report, and a team was assembled to visit the village on April 12.

As two $1 \mathrm{~L}$ packs of the PRP had recently been transferred from Australia to Laos for such a potential trial, the team carried these packs to the affected village with their personal protection-and-disinfection equipment, samplecollection materials, and a "bleeding pole" with ropes to enable the animal-restraint method commonly used in developing countries where cattle crushes are largely absent. The PRP is a blue liquid-gel matrix containing lidocaine hydrochloride $50 \mathrm{~g} / \mathrm{L}$, bupivacaine hydrochloride $5 \mathrm{~g} / \mathrm{L}$, adrenalin $1: 2,000$, and cetrimide $5 \mathrm{~g} / \mathrm{L}$. It is readily applied by spraying directly onto wounds and lesions, and has been shown to be rapidly effective. ${ }^{13}$

Following arrival at the village, the DLF staff explained the objectives of the trial and requested some affected animals be brought to the bleeding pole for restraint and treatment. This occurred, despite these animals displaying overt signs of reluctance to move and behavioral disturbances, including agitation and recumbence. A telephone video link enabled the senior author to guide the systematic clinical examination of the affected animals, the recording of observations, and the process of sampling. It was readily confirmed that these animals displayed hyperesthesia, were febrile, some displayed recumbence when restrained (Figure 1), and numerous oral, nasal, and pedal vesicular and ulcerative lesions consistent with FMD were readily observed. Samples of affected necrotic oral tissue were collected in sterile containers and blood from the jugular vein collected into serum containers using sterile vacutainers from ten affected animals, then retained and stored at $5^{\circ} \mathrm{C}$ prior to submission to the national veterinary laboratory in Vientiane.

The PRP was then applied using the no-touch spray applicator directly to coat ulcerative lesions wherever present in or around the mouth, nose, or above the hooves (Figure 2). Applications were sufficient to coat the wounds without excessive run-off, with total doses of 10-30 mL applied per animal. It was intended that in the affected animals, only a third of the pedal lesions would be treated, a third treated with chlortetracycline, and a third left untreated to enable collection of data on the rate of healing. However, once the impressive almost immediate clinical response of the PRP was 


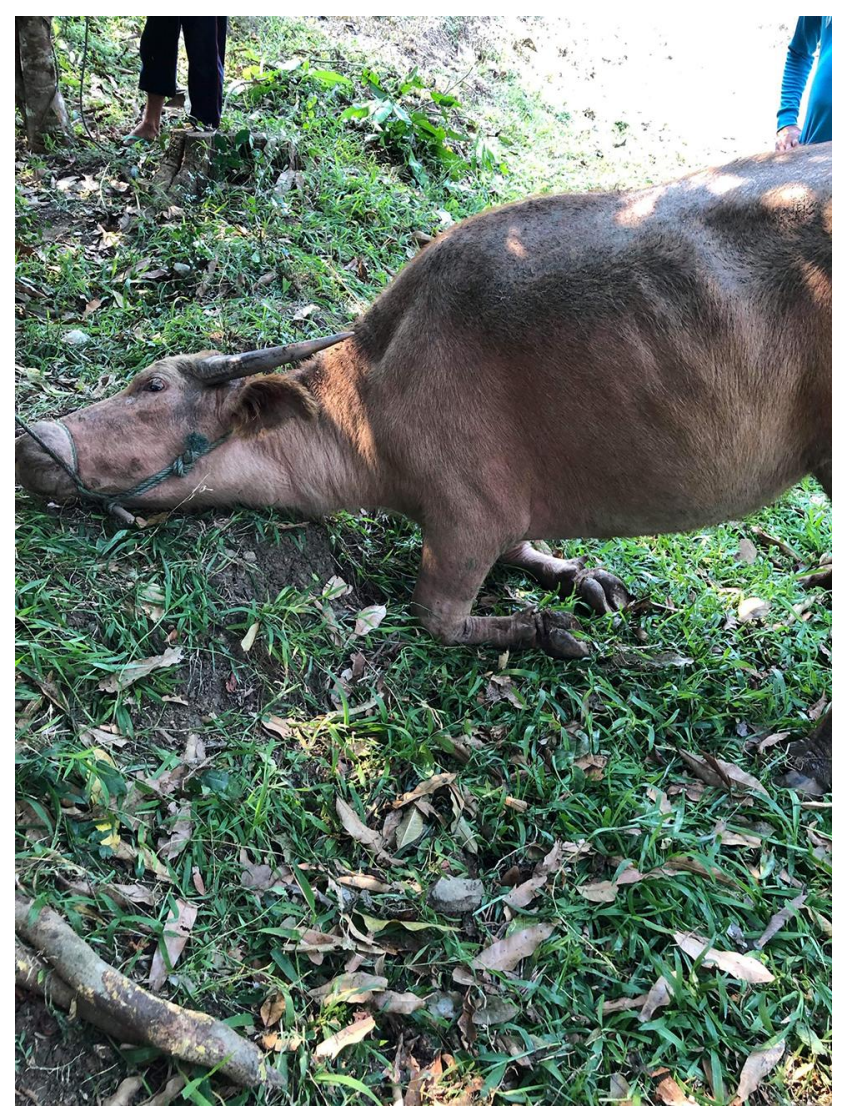

Figure I Buffalo affected with FMD displaying recumbence in preference to restraint (image from $\mathrm{C}$ Olsson).

observed, all farmers present insisted that every lesion on every affected animal needed to be treated with this "new medicine that really works". None was treated with antibiotics. Although this course of action compromised the intended comparative observations, the clear and almost immediate response to therapy in the first animals treated led to all the affected animals in the village being presented for treatment and the participating farmers insisting on treatment of all animals and lesions with the PRP. Follow-up interviews with farmers were performed by the DLF team 2 weeks later, using a simple survey questionnaire (available on request), then translated to Lao. The survey contained openended questions to encourage interactive discussions on FMD and obtain frank opinions and impressions of the farmers on the efficacy of the therapy and their willingness to purchase the PRP for future use.

\section{Results}

Following the initial treatments and observations by all of very positive clinical effects, all the farmers $(n=15)$ in Muang

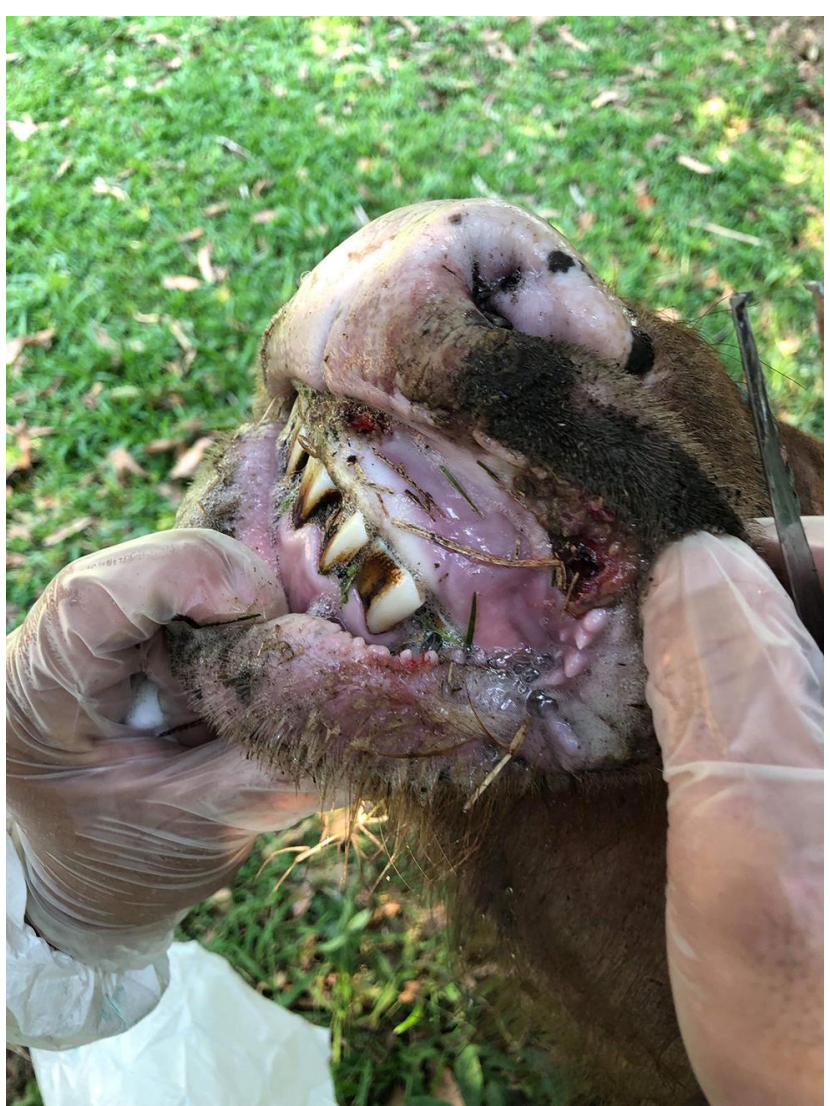

Figure 2 Examination of the oral mucosa of an FMD-affected buffalo, enabling collection of oral tissue samples from ulcerative lesions (image from $\mathrm{C}$ Olsson).

Khay with FMD-affected buffalo $(\mathrm{n}=99)$ and cattle $(\mathrm{n}=37)$ presented their affected animals for treatment. This was from a village population of 194 buffalo and 44 cows, and involved only 15 of 136 households (Table 1). The lower rate of households impacted with FMD than expected was considered attributable to FMD vaccination that had been conducted in the village 5 months previously using a commercially available bivalent $\mathrm{O}$ and $\mathrm{A}$ vaccine (Boehringer Ingelheim, France) that was residual from a previous vaccination campaign, as previously described. ${ }^{8}$ Of the village's large-ruminant population, 52 buffalo and nine cows had been vaccinated for FMD (Table 1). Although present in the village, no goats or pigs had been vaccinated for FMD, and none was observed or reported to have been affected by FMD.

Clinical findings on arrival at the village were initial observations that the normally quiet and passive animals were hyperesthetic and agitated, febrile (with rectal temperatures ranging from $\sim 39^{\circ} \mathrm{C}-41^{\circ} \mathrm{C}$ ), and reluctant to move, with several preferring recumbence to being restrained by the bleeding pole (Figure 1). Although both 
Table I Summary of FMD outbreak, Muang Khay village, Luang Prabang, Laos, April 2019

\begin{tabular}{|l|l|l|l|l|}
\hline Observation & Population, $\mathbf{n}$ & Affected, $\mathbf{n}$ & Attack rate, \% & Recent vaccination, \%* \\
\hline Families at risk & 136 & 15 & NA & NA \\
Large ruminants & 238 & 136 & $57 \%$ & $25.6 \%(61)$ \\
Buffalo at risk & 194 & 99 & $51 \%$ & $27 \%(52)$ \\
Cows at risk & 44 & 37 & $84 \%$ & $21 \%(9)$ \\
\hline
\end{tabular}

Note: *Vaccination for FMD with bivalent O/A vaccine had occurred 4-5 months previously.

FMD-vaccinated and unvaccinated buffalo and cattle were present in the village, clinical signs were observed only in the unvaccinated animals (Table 1). Clinical examinations confirmed the presence of lesions of excessive salivation from severe subacute ulcerative glossitis extending to involve the nasal mucosa, plus moderate subacute ulcerative interdigital dermatitis. These lesions were considered typical of FMD of 2-4 days' duration. Oral ulcerations were $5-15 \mathrm{~mm}$ in diameter (Figure 2). Pedal lesions were most commonly located in interdigital tissue but occasionally spread across the coronary band, and were $5-10 \mathrm{~m} \mathrm{~m}$ in diameter. Following aseptic collection of necrotic oral mucosal tissue from ten animals, $10-30 \mathrm{~mL}$ of the PRP

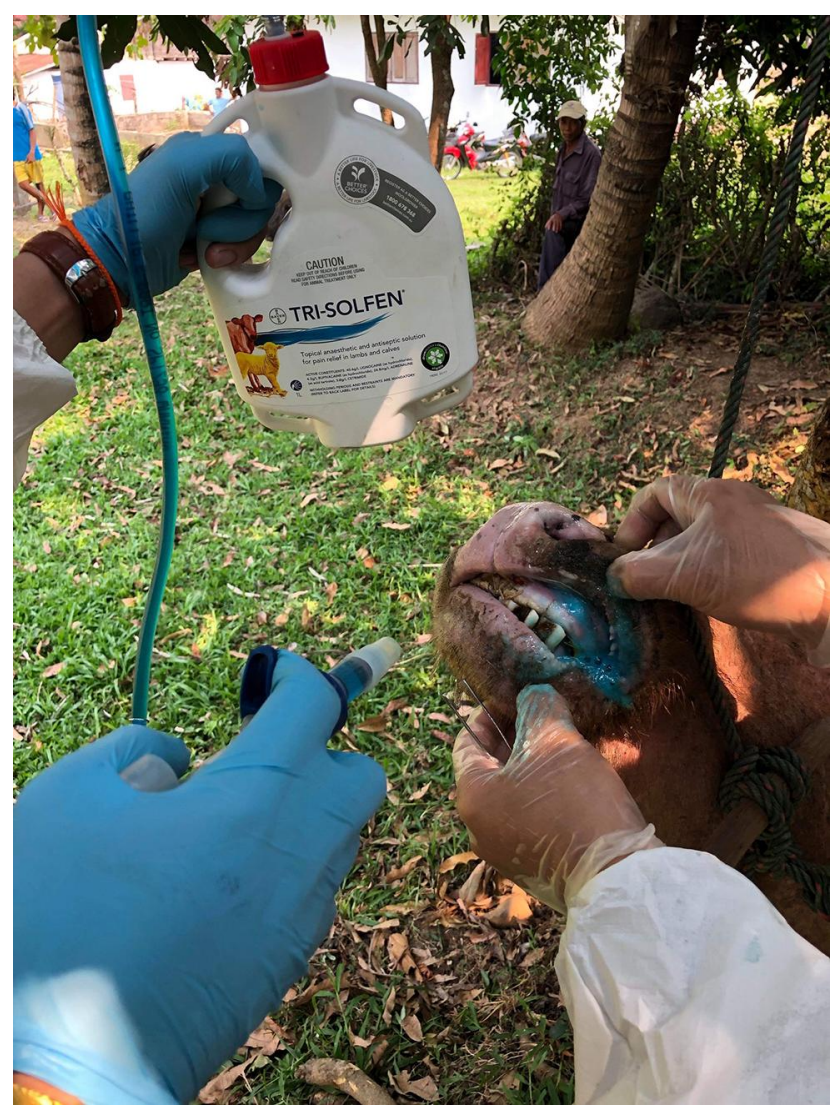

Figure 3 Application of a topical anesthetic wound formulation (PRP) to lesions in the mouth of an FMD-affected buffalo (image from $C$ Olsson). medication per animal was sprayed directly onto the oral and foot lesions (Figure 3). This resulted in immediate improvement in demeanor and locomotion of the animals. No adverse events were observed or reported and no teat lesions observed.

At the survey interview 2 weeks later, all 15 farmers advised that their treated animals were eating within 2 days and lesions had recovered within 5 days. They stated that this was a much quicker recovery than they had previously experienced and that this was a "much better medicine" compared to their previous experience with topical or parenteral antibiotics and local traditional therapies, including tree-bark astringents. When advised that the cost of treatment was $\sim 50$ cents per $1 \mathrm{~mL}$ spray of the PRP, they all reported that they were keen to purchase the product for future use. Farmers described that the treatment had clearly provided a rapid improvement in behavior indicative of a dramatic reduction in pain and animals were much easier to manage, had greatly improved healing and recovery rates, and were eating within 2 days, with lesions having recovered within 3-5 days.

The laboratory reported that due to transport delays, the tissue and blood samples were unsuitable for submission for antigen testing, virus isolation, or serological testing. However, samples collected from other outbreaks occurring in nearby villages in Luang Prabang and beyond identified the FMDV involved in the emerging outbreaks in the vicinity of this disease occurrence as involving serotype O (Figure 4). Although the isolates from Luang Prabang in 2019 remain untyped, it is presumed they are PanAsia topotype, as this was the predominant serotype circulating in the region at that time. ${ }^{1,17}$ The challenge of achieving laboratory confirmation of outbreaks of disease in developing countries where veterinary services remain underresourced is well recognized, with priorities directed to large-scale projects externally funded by international donor agencies. Previous experience in Mekong countries has required that important field observations based on detailed clinical observations of disease outbreaks, including blackleg in Laos, ${ }^{18}$ and hemorrhagic septicemia in 


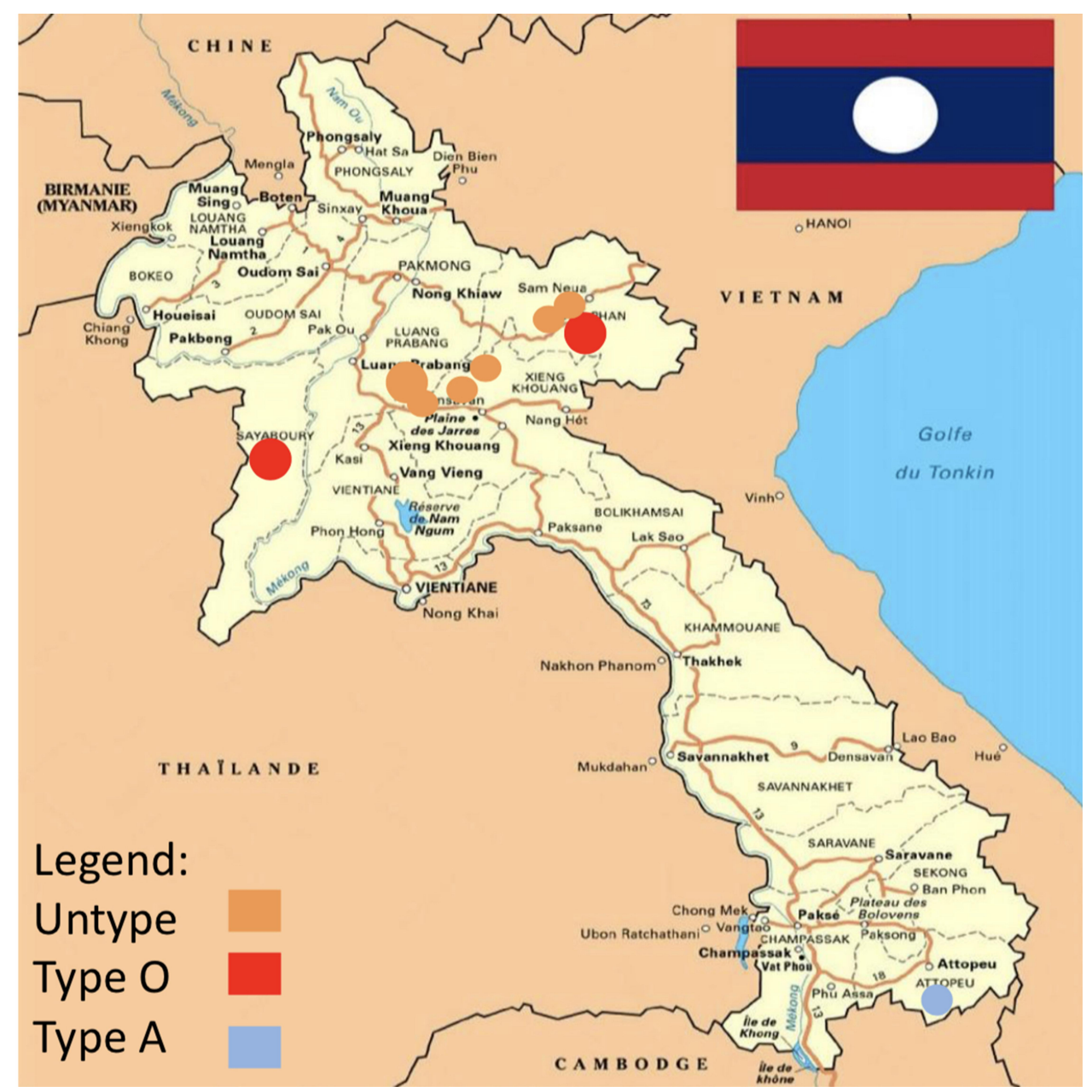

Figure 4 Map displaying distribution of reported FMD outbreaks in Laos from January 2018 to June 2019 from SEACFMD National Coordinators Meeting, June 25-27, 20I9. Notes: Reproduced with permission from Bounma. ${ }^{17}$

Cambodia, ${ }^{19}$ be successfully reported in the literature, despite the absence of laboratory confirmation due to the numerous challenges in achieving otherwise-routine analyses.

\section{Discussion}

Clinical impacts of treatment of a large cohort of FMDaffected large ruminants $(n=136)$ with the PRP containing two topical anesthetics were readily observable by all present or online on April 12, 2019. Further, follow-up interviews with the farmers indicated that response and recovery from the disease was considered markedly improved from known progression and recovery times for FMD-affected animals following use of other treatments, including antibiotics and astringents. ${ }^{1,3,7}$ As a result of these findings, the veterinary chemical registration authority of the DLF in Laos rapidly registered the product for the purpose of treating FMD, and further supplies were delivered for ongoing use. At the time of writing, a similar positive episode of treatment with this new therapy had recently occurred in Laos, involving a large outbreak of FMD in the adjacent province of Huaphan. The PRP has also now been used successfully for treating clinical FMD cases in several countries in Africa, including Cameroon, Nigeria, Niger, and Kenya, with a study in Cameroon currently in preparation for publication.

The response to therapy observed in this trial, along with absence of adverse effects, are highly consistent with the positive and prolonged pain-relieving effects of the PRP reported in cattle and sheep following blockage of nociception in the treatment of wounds from other sources, as described in a range of publications and recently reviewed. ${ }^{13-15}$ The clinical responses observed in these large ruminants with FMD, including markedly improved demeanor, locomotion, feeding, and lesion 
recovery, indicates that adopting an animal-welfare strategy for managing FMD may have important potential benefits for the health and resilience of rural communities where large ruminants are the major source of wealth and most at risk during FMD outbreaks. Of interest is that the reported improvement in resolution rate of the FMD lesions is consistent with observations and measurements conducted in sheep recovering from mulesing wounds for myiasis management in Australia that were treated with this product. ${ }^{13-15}$

Of potential importance was the observation that the readily visible, almost immediate positive clinical impacts following PRP therapy encouraged all 15 farmers in the village with affected animals to seek and insist on treatment. This motivation increases the proportion of the FMD-affected population that is administered an appropriate medication devoid of antimicrobial drugs, reducing food safety and AMR risks. Further, the positive clinical impacts may encourage improved outbreak reporting as more farmers seek access to the PRP. Identifying strategies that motivate farmers to improve disease recognition and reporting and embrace biosecurity is considered critical for the sustainability of FMD change management in developing countries. ${ }^{1,2,20,21}$ Of interest was the lower-thanexpected FMD-morbidity rate in this at-risk population, although this was considered most likely to have been due to the village having been partially vaccinated 5 months previously with a bivalent FMD vaccine (O, A; Boehringer Ingelheim). Published observations from Laos have indicated that partial vaccination of a village population may significantly lower the morbidity rate. ${ }^{19}$ Numerous investigations of FMD outbreaks in Laos have demonstrated that clinical FMD has largely been confined to large ruminants. ${ }^{1,7-11}$ Recent serological investigations have confirmed that there has been occasional transmission of FMDVs in goats in Laos, although this has not been recorded in Luang Prabang, where this outbreak occurred. ${ }^{22}$

This novel approach to FMD-outbreak management may also provide disease-control benefits from the likelihood of viricidal activity of this product against FMDVs. As the PRP has a $\mathrm{pH}$ of 2.7-2.9, if applied early in the course of the disease prior to or at the time of lesion rupture, it is likely that antiviral activity may potentially limit virus transmission during outbreaks. While the application of acidic solutions to open wounds and ulcers is generally contraindicated, as the acidity may exacerbate pain, the relatively high concentration of lidocaine $(5 \%)$ applied with bupivacaine, adrenalin, and cetrimide in a gel matrix has been shown to provide rapid and prolonged wound anesthesia from blockage of nociception, reported to be $>24$ hours, ${ }^{13}$ with the acidity potentially sufficient to destroy FMDVs without causing pain to the animal. The concentration of lidocaine is likely to be directly viricidal against FMDVs, as at concentrations ranging from $0.5 \mathrm{mg} /$ $\mathrm{mL}(0.05 \%)$ to $100 \mathrm{mg} / \mathrm{mL}(10 \%)$ lidocaine has been shown to exhibit antiviral activity against the herpes virus in cell-culture and animal-model systems. ${ }^{23}$ Further, the PRP has recently been shown to reduce viral load in cutaneous lesions in sheep caused by the Orf virus (PW, unpublished observations). As this approach may influence spread of the disease, minimizing the extent of suffering and economic losses, the potential viricidal properties of the PRP and rate of healing of treated lesions has been investigated. Since this outbreak in Laos in April 2019, clinical trials with the PRP for FMD lesions have been conducted in several countries in Africa, with all reports indicating very high (100\%) acceptance of this therapy by farmers. A study in Cameroon confirmed that cattle affected by FMD and treated with the PRP exhibited reduced pain and had improved welfare outcomes, with measurable reductions in time to recovery and negative productivity impacts, plus high-level appreciation by farmers and livestock extension personnel of this therapeutic approach (PW, unpublished observations).

The improved behaviors and speedier healing of lesions, plus acceptance of a product for FMD that was developed for pain relief during aversive livestockhusbandry procedures, is evidence that smallholder farmers display concern for enhancing the welfare of their livestock when provided with access to a product that shows high-level efficacy in reducing animal suffering. Similar observations have been noted in Australia, with $\sim 80 \%$ adoption of use by sheep farmers of this PRP for surgical breech modification for prevention of flystrike. ${ }^{13-15}$ Of interest, once there was awareness of the availability of the PRP, demand for treatment rapidly increased with presentation of the entire population of affected animals and insistence that all lesions be treated. This enabled an increased level of animal examination and specimen collection than is typically the case in developing countries, where there is commonly a level of resistance to such interventions. If this is translated to improved reporting of FMD outbreaks to gain access to this inexpensive welfare-appropriate therapy for FMD, the use of the PRP has the potential to be a driver for 
improved regional disease surveillance and reduced socioeconomic impacts of FMD outbreaks.

Importantly, this PRP is a nonantimicrobial therapy. It offers a more clinically effective approach that potentially addresses AMR issues from current antimicrobial-treatment approaches that have been promulgated widely as potentially reducing the risks of secondary bacterial infections. This paradigm was recently challenged in Spain, where a lowered rate of secondary infection occurred following application of this PRP in an ovine surgical tail-docking study, enabling removal of the routine antibiotic cover usually provided during this intervention. ${ }^{24} \mathrm{~A}$ paradigm shift from routine treatment of FMD and other lesions with antimicrobials that risk AMR, to a new approach that improves animal welfare and may motivate farmer interest in disease reporting, assisting transboundary diseaseoutbreak management, is proposed.

\section{Conclusion}

This is the first scientific report of a novel pain-relief therapy developed for aversive livestock procedures applied to lesions during a large outbreak of FMD, which occurred in Laos and involved 136 affected cattle and buffalo. The very positive and almost immediate clinical impacts suggest that the widespread adoption of this welfare-focused therapy should be encouraged in FMD management. This innovation may change the FMDtreatment paradigm from the inappropriate and expensive antimicrobials currently in use for a viral disease, to one of improved welfare that encourages farmers to report disease in seeking a treatment that reduces suffering and is of clear clinical benefit to affected animals, while reducing AMR and food-safety risks. Videos, images, and other information, including a treatment-trial protocol and survey, are freely available from the corresponding author on request.

\section{Abbreviations}

FMD, foot-and-mouth disease; OIE, Office International des Epizooties (World Organisation for Animal Health); PRP, pain-relief product (Tri-Solfen); SEACFMD, South East Asia and China Foot-and-Mouth Disease.

\section{Acknowledgments}

The cooperation of the farmers and the staff of the DLF involved in this work, particularly $\mathrm{Mr}$ Borkeo and $\mathrm{Mr}$ Kong, is gratefully acknowledged, as was the advice of Ms Susan Martin of the Luang Prabang Buffalo Dairy in initially alerting us to the outbreak. Mr Charles Olsson of Four Seasons Company Australia was in attendance at the trial and provided us with real-time videos of the clinical findings and vision and images of the responses of animals and farmers to the use of this new therapy. Provision of Tri-Solfen by Animal Ethics Australia (a subsidiary of Medical Ethics Australia) for use in the trial is also acknowledged.

\section{Disclosure}

The authors report no conflicts of interest in this work. The extensive studies evaluating Tri-Solfen and other therapies for aversive animal-husbandry interventions that occurred prior to this study were funded by an Australian Research Council Linkage Grant from the Australian government with financial contributions from Animal Ethics Australia and Bayer Animal Health Australia. However, this study did not receive funding from either of these companies, nor did they have a role in study design, data collection and analysis, decision to publish, or preparation of the manuscript.

\section{References}

1. Blacksell SD, Siengsanan-Lamont J, Kamolsiripichaiporn S, Gleeson L, Windsor PA. A history of FMD research and control programmes in Southeast Asia: lessons from the past informing the future. Epidem Infect. 2019;147:E171. doi:10.1017/S09502688 19000578

2. Young JR, Evans-Kocinski S, Bush RD, Windsor PA. Improving smallholder farmer biosecurity in the Mekong Region through change management. Transbound Emerg Dis. 2015;62:491-504. doi:10.1111/ tbed.12181

3. Nampanya S, Khounsy S, Phonvisay A, Young JR, Bush RD, Windsor PA. Financial impact of foot and mouth disease on large ruminant smallholder farmers in the Greater Mekong Subregion. Transbound Emerg Dis. 2013;62:555-564. doi:10.1111/tbed.12183

4. Knight-Jones TJD, Rushton J. The economic impacts of foot and mouth disease - what are they, how big are they and where do they occur? Prev Vet Med. 2013;112:161-173. doi:10.1016/j.prevetmed. 2013.07.013

5. Gerber PJ, Mottet A, Opio CI, Falcucci A, Teillard F. Environmental impacts of beef production: review of challenges and perspectives for durability. Meat Sci. 2015;1909:2-12. doi:10.1016/j.meatsci.2015. 05.013

6. Windsor PA. Perspectives on Australian animal health aid projects in South-East Asia. Transbound Emerg Dis. 2011;58:375-386. doi:10.1111/j.1865-1682.2011.01216.x

7. Nampanya S, Khounsy S, Abila R, Dy C, Windsor PA. Household financial status and gender perspectives in determining the financial impact of foot and mouth disease in Lao PDR. Transbound Emerg Dis. 2014;63:398-407. doi:10.1111/tbed.12281

8. Nampanya S, Khounsy S, Abila R, Windsor PA. Implementing large foot and mouth disease vaccination programmes for smallholder farmers: lessons from Lao PDR. Epidemiol Infect. 2018;146(6):2086-2095. doi:10.1017/S0950268818002443

9. Miller CAJ, Young JR, Nampanya S, et al. Risk factors for emergence of exotic foot-and-mouth disease O/ME-SA/Ind-2001d on smallholder farms in the Greater Mekong Subregion. Prev Vet Med. 2018;159:115-122. doi:10.1016/j.prevetmed.2018.09.007 
10. Nampanya S, Khounsy S, Rast L, Windsor PA. Promoting transboundary animal disease risk management via a multiple health and husbandry intervention strategies in upland Lao PDR. Trop an Health Prod. 2014;46:439-446. doi:10.1007/s11250-013-0511-3

11. Nampanya S, Khounsy S, Rast L, Young JR, Bush RD, Windsor PA. Progressing smallholder large-ruminant productivity to reduce rural poverty and address food security in upland Northern Lao PDR. An Prod Sci. 2014;54:899-907. doi:10.1071/AN13180

12. MacPhillamy I, Young J, Siek S, et al. Improving Village Animal Health Worker participation in national disease surveillance systems: a case study from Cambodia. Transbound Emerg Dis. 2019;67 (2):967-978. doi:10.1111/tbed.13432

13. Roberts CD, Windsor PA. Innovative pain management solutions in animals may provide improved wound pain reduction during debridement in humans: an opinion informed by veterinary literature. Int Wound J. 2019;16(4):968-973.

14. Windsor PA, Lomax S. Addressing welfare concerns in control of ovine cutaneous myosis in sheep in Australia. Small Rum Res. 2013;110:165-169.

15. Windsor PA, Lomax S, White P. Progress in pain management to improve small ruminant farm welfare. Small Rum Res. 2016;142:55-57. doi:10.1016/j.smallrumres.2016.03.024

16. Stilwell GT, Ferrador AM, Santos S, Domingues JM, Carolin N. Use of topical local anesthetics to control pain during treatment of hoof lesions in dairy cows. J Dairy Sci. 2019;102:6383-6390. doi:10.3168/jds.2018-15820

17. Bounma P. Laos country report. SEACFMD National coordinators meeting. Ulaan Bataar, Mongolia; June 25-27, 2019. Available from: https://rr-asia.oie.int/wp-content/uploads/2019/12/session-2_reportsof-applicant-countries-for-pcp_laos.pdf. Accessed August 23, 2020.
18. Nampanya S, Khounsy S, Dhand NK, Bush RD, Windsor PA. Financial impact of an outbreak of clinically diagnosed Blackleg a case study from Lao PDR. Vet Med Sci. 2019;2019(5):118-128. doi:10.1002/vms3.152

19. Kawasaki M, Young JR, Suon S, Bush RD, Windsor PA. The socioeconomic impacts of clinically diagnosed Haemorrhagic Septicaemia on smallholder large ruminant farmers in Cambodia. Transb Emerg Dis. 2015;62:535-548. doi:10.1111/tbed.12174

20. Young JR, Suon S, Olmo L, et al. Investigation of smallholder farmer biosecurity and implications for sustainable foot-and-mouth disease control in Cambodia. Transbound Emerg Dis. 2017;66:1-13.

21. Rast L, Windsor PA, Khounsy S. Limiting the impacts of foot and mouth disease in large ruminants in northern Lao People's Democratic Republic by vaccination: a case study. Transbound Emerg Dis. 2010;57:147-153. doi:10.1111/j.1865-1682.2010.01099.x

22. Singanallur N, Nampanya S, MacPhillamy I, et al. Serological evidence of foot-and-mouth disease infection in goats in Lao PDR. Front Vet Sci. 2020;7:1-11. doi:10.3389/fvets.2020.00544

23. Haines HG, Dickens CB, Brigham DP. Antiviral pharmaceutical preparations and methods for their use. Patent US 4628063A. 1986.

24. Ferrer LM, Lacasta D, Ortín A, et al. Impact of a topical anaesthesia wound management formulation on pain, inflammation and reduction of secondary infections after tail docking in lambs. Animals. 2020;10 (8):1255. doi:10.3390/ani10081255

\section{Publish your work in this journal}

Veterinary Medicine: Research and Reports is an international, peerreviewed, open access journal publishing original research, case reports, editorials, reviews and commentaries on all areas of veterinary medicine. The manuscript management system is completely online and includes a very quick and fair peer-review system. Visit http://www.dovepress.com/testimonials.php to read real quotes from published authors.

Submit your manuscript here: http://www.dovepress.com/veterinary-medicine-research-and-reports-journal 